\title{
Obstacles in Installation and Recommendations INFO Sheet D2
}

\begin{tabular}{l|l} 
Description: & $\begin{array}{l}\text { Overview of current obstacles in installation, installers recommendations and } \\
\text { wishes in respect to an improvement of current practices on the basis of Task } 54 \\
\text { installation survey from 2016-2017. }\end{array}$ \\
\hline Date: & 15/09/2018 \\
\hline Authors: & S. Saile, Fraunhofer ISE, D. Mugnier, TECSOL, D. Philippen, SPF \\
\hline Download possible at: & http://task54.iea-shc.org/
\end{tabular}

\section{Introduction}

Task 54 investigated obstacles in installation of solar-thermal systems and developed recommendations for improvement of the installation process by evaluating respective questionnaires from installation companies in Austria, Switzerland, France, Romania, Denmark, the Netherlands and Germany. From feedback by 23 installers from 7 countries, recommendations and wishes for working with solar thermal systems can be deduced. This info sheet provides insight on soft factors that influence the day-to-day business of solar thermal installation and highlights recommendations for a positive transformation of future installation routines. The info sheet is a direct follow-up to info sheets D 1 "Overview of Installation Costs" (http://task54.iea-shc.org/info-sheets).

\section{Criteria for the Choice of Manufacturers}

One of the questions that are central to the installation questionnaire is on the choice of manufactures of the system or applied components. Which factors are the most decisive when it comes to choosing a solar thermal system? Are there framework contracts or other factors influencing an installer's choice for cooperation?

The investigation shows that a high majority of installers prefers solar thermal sets that are easy to install with convenient installation sets. Competitive prices and customer wishes come second, whilst others mention best and long-term quality as decisive factors, even if more expensive. Building owner requirements were mentioned once in connection to specs in calls for tenders in France.

In general, one can say that achieving a maximum margin with least risk is on the bottom of any decision for or against a certain system type and manufacturer. Familiarity with specifics of one manufacturer may speed up the time for installation. Routine and experience make the process smooth and predictable for both costumers and installation partner.

\section{Time Consuming Parts during Installation}

How decisive installation time is, is shown by the question on the most time-consuming parts in installation. Big agreement amongst the countries appears to be on the fact that major time losses occur in connection to piping as well as to roof installation in general. These are important indications for technical optimizations or improvements in the organization of work as shown in figure 1. 


\section{Obstacles in Installation and Recommendations INFO Sheet D2}

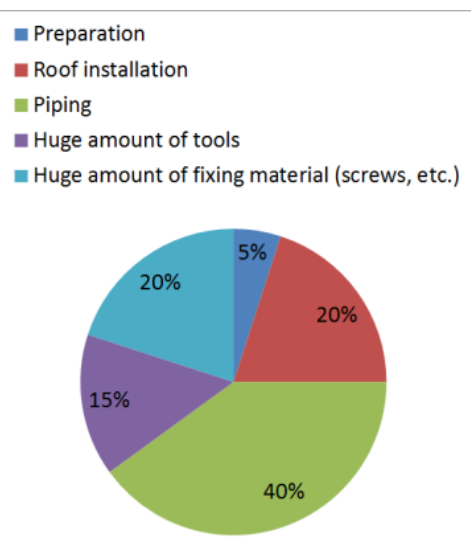

Fig 1. Percentage distribution of time consuming factors for installation.

\section{Recommendations for Improvements}

Standardized mounting for all kinds of systems ranks first, accompanied by suggestions for useful collector fixing kits or detailed mounting videos explaining crucial steps in the installation process. An increased and open communication amongst all stakeholders, better cooperation and sharing schemes of "lessons learnt" are also highlighted by the respondents. These could also be acquired from the installation of large area collectors with specialized and efficient plumbing and heating installers. Wireless sensors and an increase in electrical wiring efficiency is another wish, uttered by French partners.

\section{What Do Installers Think of...}

\section{Subcontracting of Collector Installation}

Most respondents in Central European countries are in favour of subcontracting installation with specialized installers. Interestingly enough, this case is different for France were subcontracting was not seen as an option, this opinion is shared by colleagues in Romania. The Netherlands uttered a new approach as they are for a shared model where the involvement of subcontractors is an option but not a must.

\section{Plug \& Play Installation}

Plug \& Play installation appears to be one of the 'big topics' in installation, as all respondents are in favour of one and the same easy and efficient installation process for all system types alike.

Concerns, however, were uttered when it comes to the quality of installation sets and practices, as plug \& play only makes sense when the quality stays the same or is improved. Others see a danger in 'do it yourself' attitudes fostered by plug \& play installation. Mistakes in installation by unexperienced laymen should be avoided. 


\section{Obstacles in Installation and Recommendations INFO Sheet D2}

\section{Standardization}

Yes or 'why not' was stated in nearly all countries and mostly also a speeding up the installation process was assumed. Yet, here again, concerns with quality were raised. Some respondents are hesitant as they see a probability that careless mistakes would rise with standardization. One respondent sees more risk than use for the sector, especially as piping and roofs are always different and might not be supported with a "one-fits-all" solution.

\section{Package Label}

As rather new topic, the impact of the package label ${ }^{1}$ was also pursued in the survey. None of the respondents sees any negative implications of problems for the installation business. What is more, they think that in contrast to the initial fear, no one in the sector is taking the label seriously yet, as neither customers nor competitors would be able and willing to pay any additional costs.

\section{a Possible Effect of Energy Efficiency Classes on the Installation Price.}

A negative impact on system prices is not expected as even without label, highest efficiency is always the goal for any system within the confines of the customer's financial capacities.

\section{Conclusion}

The survey shows that the installation of solar thermal systems can be significantly improved by a clear simplification leading to an acceleration of the installation process itself. Technical suggestions centre on standardized mounting sets and plug \& play solutions. These technical suggestions are flanked by wishes for knowledge exchange and capacity building which shows that there is still room for improvement when it comes to the specialization of workers. Outsourcing of the installation of solar thermal systems appears to be attractive for a large number of respondents and further shows the need for specialization of the profession for solar thermal applications.

\section{References :}

Mugnier, D. et al. Info Sheet D 1 "Overview of Installation Costs" (http://task54.iea-shc.org/info-sheets)

\footnotetext{
${ }^{1}$ The "package label" is the label applicable to a system, i.e., the combination of different components of a system. There can be packages of water heaters with solar; space heating equipment and of combination systems (used both for space and water heating).More information on: http://www.label-pack-a-plus.eu/home/energy-label/energylabelling/description-of-the-package-label/
} 